Bull. Chem. Soc. Ethiop. 2018, 32(3), 469-479.

ISSN 1011-3924

(C) 2018 Chemical Society of Ethiopia and The Authors

Printed in Ethiopia

DOI: https://dx.doi.org/10.4314/bcse.v32i3.6

\title{
PLANT MEDIATED SYNTHESIS OF SILVER NANOPARTICLES AND THEIR BIOLOGICAL APPLICATIONS
}

\author{
Natasha Anwar ${ }^{1}$, Mohib Shah ${ }^{2 *}$, Samreen Saleem ${ }^{3}$ and Hadia Rahman ${ }^{2}$ \\ ${ }^{1}$ Department of Chemistry, Abdul Wali Khan University Mardan, 23200, Pakistan \\ ${ }^{2}$ Department of Botany, Abdul Wali Khan University Mardan, 23200, Pakistan \\ ${ }^{3}$ Department of Botany, Women University Swabi, Pakistan
}

(Received December 01, 2017; Revised March 13, 2018; Accepted November 5, 2018)

\begin{abstract}
The green synthesis of nanoparticles using plants and their extracts is considered as a representative approach in material synthesis for environmental benignity. Numerous metal nanoparticles with potential bioactivities have been prepared based on plant extracts. In this paper, we report an eco-friendly technique for the preparation of silver nanoparticles using plant extract of Justicia diffusa Willd. and the evaluation of their antioxidant, antidiabetic, and cytotoxicity activities. UV-visible spectroscopy, transmission electron microscopy, scanning electron microscopy and atomic force microscopy analysis were used to characterize the morphology and size of silver nanoparticles. The stability of silver nanoparticles toward acidity, alkalinity, salinity and temperature showed that they remained stable at room temperature for more than two months. UV-vis spectrum of the aqueous medium containing silver nanoparticles showed an absorption peak at around $420 \mathrm{~nm}$. The scanning electron microscopy analysis of the silver nanoparticles showed that they have a uniform spherical shape with an average size in the range of 40-78 $\mathrm{nm}$. This was confirmed by transmission electron microscopy analysis which showed an average size of about 50 $\mathrm{nm}$. Thus green system showed better capping and stabilizing agent for the fine particles. Further 1-diphenyl-2picrylhydrazl radical in Justicia diffusa mediated silver nanoparticles showed a maximum activity of $67 \%$ at concentration of $200 \mu \mathrm{g} / \mathrm{mL}$. Hydrogen peroxide scavenging assay in Justicia diffusa mediated silver nanoparticles showed a maximum activity of $89 \%$ at concentration of $200 \mu \mathrm{g} / \mathrm{mL}$. Reducing power of Justicia diffusa silver nanoparticles exhibited a higher activity of $246 \mu \mathrm{g} / \mathrm{mL}$ at concentration of $200 \mu \mathrm{g} / \mathrm{mL}$. These NPs showed the cytotoxic effects against brine shrimp (Artemia salina) Nauplii with a value of $35 \%$ and LD value of $271 \mu \mathrm{g} / \mathrm{mL}$. The AgNPs synthesized using Justicia diffusa Willd. extract also show remarkable antidiabetic activities.
\end{abstract}

KEY WORDS: Justicia diffusa, Nanoparticles, TEM, SEM, AFM

\section{INTRODUCTION}

The field of nanotechnology has perceived impressive advances in various aspects such as the synthesis of nanoscale matter and understanding/applying their physicochemical and optoelectronic properties. Novel approaches for the organization of nanoparticles into enumerate superstructures ensured that nanotechnology plays an increasingly important role in many key technologies of the new millennium [1]. Different types of nanoparticles can be synthesized by using physical, chemical and biological methods. The main drawback with the chemical and physical methods of silver nanoparticle formation is that they are costly and also involve the use of toxic, hazardous chemicals and they contain potential environmental and biological stakes [2]. Therefore the need for the development of clean, nontoxic and eco-friendly procedures for synthesis of nanoparticles motivated researchers seriously looking at biological systems. Both plant and animal kingdom of unicellular and multicellular organisms produce inorganic materials [3]. Some of the well-known examples include magnetotactic bacteria (which synthesize magnetite nanoparticles) [4], diatoms (which synthesize siliceous materials) [5] and earthworm [6]. The option to achieve biotechnological applications is to use plants [7], fungi [8] and bacteria [9] to synthesize nanoscale materials. Biologically synthesized silver nanoparticles could be of immense use due to applications like to transform the physical, optical and

*Corresponding author. E-mail: mohibshah@awkum.edu.pk

This work is licensed under the Creative Commons Attribution 4.0 International License 
electronic properties of a compound, treatment of cancer, antimicrobial coatings of paint, as medical devices, textiles, also biological or chemical sensing, also possess antiviral, antifungal, anti-inflammatory and antiplatelet activities [5, 10]. In focusing on the biosynthesis of nanomaterials, it was reported that Helicteres isora root extract when treated with concentrated aqueous solution of $\mathrm{AgNO}_{3}$, was able to reduce the $\mathrm{Ag}^{+}$ions and form silver nanoparticles of well-defined size and distinct morphology [11]. The exact reaction mechanism leading to the synthesis of silver nanoparticles by plants is yet to be clarified. Isaac and coworkers have also used fruit extract of Averrhoa bilimbi Linn. for the green synthesis of silver and gold nanoparticles [12]. Saxena and co-workers also used Ficus benghalensis leaf extract and prepared silver nanoparticles within 5 min of reaction time without using any harsh conditions [13]. Developing on the strategy to enlarge the scope of plants in the synthesis of nanomaterials, we demonstrate herein that the Justicia diffusa plant, when exposed to aqueous $\mathrm{AgNO}_{3}$ solution, causes the reduction of the metal ions and formation of silver nanoparticles of $50 \mathrm{~nm}$ size.

Justicia diffusa belongs to the family acanthaceae. It is a much branched herb with striate, quadrangular, sparsely hairy twigs. It has petiolate leaves with elliptic lanceolate lamina. Cystoliths are irregularly scattered. The inflorescences are terminal or axillary. The flowers are pink or pale purple and bracteates (Figure 1). Its blooming season is from April-August. It is distributed in Pakistan, Nepal, India, Burma, Thailand and Sri Lanka [14].

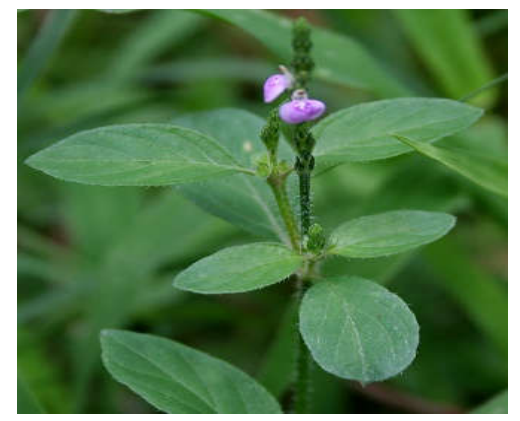

Figure 1. The plant, Justicia diffusa Willd., used in this study.

\section{EXPERIMENTAL}

Silver nitrate $\left(\mathrm{AgNO}_{3}\right)$, hydrochloric acid $(\mathrm{HCl})$ and sodium hydroxide $(\mathrm{NaOH})$ were purchased from Merck. Deionized distilled water $\left(\mathrm{dd}_{2} \mathrm{O}\right)$ was used for all reactions, solution preparations and analysis purpose and was obtained from Millipore Milli-Q system (Millipore, Bedford, MA, USA). Perkin-Elmer spectrophotometer (Lamda 25) was used initially for optimization study of plant/salt ratio for study of better samples. FT-IR spectra were recorded on IR Affinity. Shimidzo (Japan). SEM images were recorded by using JEM 2100, jeol (japan) with high and low vacuum. For optimization of reaction samples, $\mathrm{pH}$ of the medium was also set using $\mathrm{pH}$ meter Milwaukee, MW802, pH/EC/TDS meter. Atomic force microscopy (AFM) analysis for synthesized NPs was done by using the instrument NOVA NT-MDT SOLVER NEXT, Russia. TEM analysis was performed by using HR-3100 advanced $0 \mathrm{kV}$ TEM from Hitachi (Japan).

\section{Collection of plant material}

Justicia diffusa Willd. was freshly collected from various localities in District Mardan in the Khyber Pakhtunkhwa of Pakistan. It was collected in the months of March, April and June. Samples were brought to the laboratory and were clean thoroughly with fresh water to remove 
the debris and other micro flora and fauna. The plant samples were identified with the available literature of flora of Pakistan [14].

\section{Preparation of crude extract of Justicia diffusa Willd.}

Plant leaf extract of Justicia diffusa Willd. was prepared by taking $5 \mathrm{~g}$ of the leaves and properly washed in distilled water. They were then cut into fine pieces and taken in a $250 \mathrm{~mL}$ Erlenmeyer flask with $100 \mathrm{~mL}$ of sterile distilled water. It was boiled and filtered. The extract was stored at $4{ }^{\circ} \mathrm{C}$ and used within a week.

\section{Synthesis of silver nanoparticles stabilized with Justicia diffusa Willd.}

Justicia diffusa Willd. was also used to further explore the green synthesis and stability of AgNPs. $100 \mathrm{~mL}$ of the prepared solution of plant was taken in a volumetric flask. $1 \mathrm{mM} \mathrm{AgNO}_{3}$ solution was also prepared for the reaction in a separate vial. Both solutions were taken in a vial with different salt/plant molar ratios, such as $1: 1,2: 1 \ldots 10: 1$, etc., for different reactions. The reaction mixtures were kept on stirring for 4 hours at room temperature. The change in color, which gives a primary indication of nanoparticles formation, for each reaction was observed. UV-VIS spectra were recorded on spectrophotometer. A particular absorption plasmon band in the region of 400 to 500 showed the presence of silver nanoparticles. The silver nanoparticles were isolated by centrifugation at $14000 \mathrm{rpm}$. The solid Ag-NPs were collected for FTIR, SEM, TEM and AFM studies.

\section{Biological activities}

To see the potential biomedical use of these green synthesized/stabilized nobel metal NPs, DPPH antioxidant assay, hydrogen peroxide $\left(\mathrm{H}_{2} \mathrm{O}_{2}\right)$ scavenging assay, reducing power, brine shrimp cytotoxic assay and alpha-amylase inhibitory assay were also investigated.

\section{DPPH antioxidant assay}

The scavenging activity of DPPH free radical of plant extracts were achieved by using method described by [15] and adapted by [16]. Aliquots of $200 \mu \mathrm{L}$ of each test sample $(200 \mu \mathrm{g} / 0.5 \mathrm{~mL}$, $66.6 / 0.5 \mathrm{~mL}, 33.3 / 0.5 \mathrm{~mL}, 7.4 / 0.5 \mathrm{~mL}) \mu \mathrm{g} / \mathrm{mL}$ of all extracts were stirred with $2800 \mu \mathrm{L}$ of DPPH $3.2 \mathrm{mg} / 100 \mathrm{~mL}$ solution in test tube. After $1 \mathrm{~h}$ of incubation in dark at room temperature, absorbance of each reaction mixture was taken at $517 \mathrm{~nm}$ by using UV-visible spectrophotometer. In negative control $200 \mu \mathrm{L}$ of respective solvent (methanol) and $2800 \mu \mathrm{L}$ of DPPH solution were used and in blank methanol were used. In positive control, ascorbic acid is used as same concentrations of plant sample. Each experiment was repeated in triplicates. The DPPH scavenging activity was calculated by using given formula and graphical method was used to calculate the $\mathrm{IC}_{50}$ value.

Percentage inhibition $=\left[\left(\mathrm{A}_{\mathrm{c}}-\mathrm{A}_{\mathrm{s}}\right) / \mathrm{A}_{\mathrm{c}}\right] \times 100$

where, $A_{c}$ is negative control absorbance and $A_{s}$ is absorbance of sample. Same method was used to determine the antioxidant activity of AgNPs stabilized with Justicia diffusa Willd. extract.

\section{Hydrogen peroxide scavenging assay}

The capacity of the plant extract and silver nanoparticles capped with Justicia diffusa Willd. to scavenge $\mathrm{H}_{2} \mathrm{O}_{2}$ was determined according to the method of [17]. A solution of $2 \mathrm{mM} \mathrm{H}_{2} \mathrm{O}_{2}$ was prepared in $50 \mathrm{mM}$ phosphate buffer $(\mathrm{pH}$ 7.4). An aliquot of $100 \mu \mathrm{L}$ of the sample was 
transferred to an Eppendorf tube to have final concentration in reaction mixture of 200, 66.6, 22.2 and $7.4 \mu \mathrm{g} / \mathrm{mL}$ and the volume was made up to $400 \mu \mathrm{L}$ with $50 \mathrm{mM}$ phosphate buffer ( $\mathrm{pH}$ 7.4). After addition of $600 \mu \mathrm{L}$ of $\mathrm{H}_{2} \mathrm{O}_{2}$ solution, tubes were vortexed and absorbance of $\mathrm{H}_{2} \mathrm{O}_{2}$ at $230 \mathrm{~nm}$ was determined after $10 \mathrm{~min}$, against a blank. Ascorbic acid was used as positive control. The percentage $\mathrm{H}_{2} \mathrm{O}_{2}$ scavenging ability of samples (extract/fraction) was then calculated by using the following equation:

$\mathrm{H}_{2} \mathrm{O}_{2}$ scavenging activity $=\left[1-\mathrm{A}_{\mathrm{s}} / \mathrm{A}_{\mathrm{c}}\right] \times 100$

where, $A_{s}$ is absorbance of sample, $A_{c}$ is absorbance of control. All experiments were performed in triplicate.

Reducing power

The reducing power of was evaluated according to procedure reported by [18]. The reducing potential of the plant extract sample and AgNPs was determined by using $200 \mu \mathrm{L}$ aliquot of extract prepared in DMSO mixed with $500 \mu \mathrm{L}$ of $2 \mathrm{M}$ phosphate buffer at $\mathrm{pH} 6.6$ and $500 \mu \mathrm{L}$ of $1 \%$ potassium ferricyanide $\left[\mathrm{K}_{3} \mathrm{Fe}(\mathrm{CN})_{6}\right]$. The mixture was incubated at $50{ }^{\circ} \mathrm{C}$ for $20 \mathrm{~min}$. A volume of $500 \mu \mathrm{L}$ of $10 \%$ trichloroacetic acid was added to the mixture, which was then centrifuged at $3000 \mathrm{rpm}$ for $10 \mathrm{~min}$. The upper layer of the mixture $(500 \mu \mathrm{L})$ was mixed with equal volume of distilled water and $100 \mu \mathrm{L}$ of $0.1 \%$ ferric chloride $\left(\mathrm{FeCl}_{3}\right)$. Absorbance was measured at $700 \mathrm{~nm}$. Blank was prepared by adding $200 \mu \mathrm{L}$ of DMSO instead of the extract and AgNPs. The reducing power of each sample was expressed as ascorbic acid equivalent. All experiments were performed in triplicate.

Brine shrimp cytotoxic assay

The toxicity of Justicia diffusa Willd. extract and AgNPs capped with Justicia diffusa Willd. were determined by brine shrimp cytotoxicity assay as reported by [19]. $2.5 \mathrm{~mL}$ of plant extract and AgNPs solution was added to $2.5 \mathrm{~mL}$ of sea water containing 10 nauplii. Prepared plant extract and AgNPs in different concentrations can be checked by implementing the assured volume of the plant extract and AgNPs in vials have brine solution [20]. Selective ten brine shrimp nauplii were added into every sample vial and artificial sea water is added to adjust the final volume of every vial. Each vial consists of the $0.5 \mathrm{~mL}$ of plant extract and AgNPs and 4.5 $\mathrm{mL}$ of manufactured sea water and 10 nauplii of brine shrimp [19]. Total volume of test solution is $5 \mathrm{~mL}$ in each vial. The experiments were performed in triplicate. All sample vials were kept uncovered under light source for next $24 \mathrm{hrs}$ in incubator at room temperature. After $24 \mathrm{~h}$, the number of alive shrimps were counted and noted carefully by using magnifying glass.

Alpha amylase inhibition assay

Alpha-amylase inhibitory activity of extract and AgNPs were performed according to the previously reported method [21] with modest modification. In a test tube, reaction mixture containing $350 \mu \mathrm{L}$ phosphate buffer $(50 \mathrm{mM}, \mathrm{pH}=6.8), 70 \mu \mathrm{L}$ alpha-amylase $(10 \mathrm{U} / \mathrm{mL})$ [SRL] and $140 \mu \mathrm{L}$ of varying concentrations $(7.4,22.2,66.6,200 \mu \mathrm{g} / \mathrm{mL})$ of Justicia diffusa Willd. plant extract and AgNPs capped with Justicia diffusa Willd. was pre-incubated at $37^{\circ} \mathrm{C}$ for 10 min. Then $140 \mu \mathrm{L}$ soluble starch $(0.05 \%)$ [Hi Media] was added as a substrate and incubated further at $370{ }^{\circ} \mathrm{C}$ for $15 \mathrm{~min}$. The reaction was stopped by adding $140 \mu \mathrm{L} 1 \mathrm{~N} \mathrm{HCl}$, followed by addition of $700 \mu \mathrm{L}$ iodine reagent $\left(5 \mathrm{mM} \mathrm{I}_{2}\right.$ and $5 \mathrm{mM} \mathrm{KI}$, stored in amber colored bottle). The absorbance was read at $620 \mathrm{~nm}$ using UV-visible spectrophotometer. Each experiment was performed in triplicates, along with appropriate blanks. Acarbose at various concentrations (7.4, 
$22.2,66.6,200 \mu \mathrm{g} / \mathrm{mL}$ ) was included as a standard. Negative control without extracts was set up in parallel. The result is expressed as percentage inhibition, which was calculated as,

$\%$ Inhibition $=\mathrm{A}_{\text {test }}-\mathrm{A}_{\text {negative control }} / \mathrm{A}_{\text {test }} \times 100$

where, $\mathrm{A}$ is absorbance and the result were also expressed as $\mathrm{IC}_{50}$ value [21].

\section{RESULTS AND DISCUSSION}

Optimization of $\mathrm{AgNO}_{3}$ /plant ratios for Ag-NPs stabilized with Justicia diffusa Willd.

UV-Visible spectra of AgNPs stabilized with Justicia diffusa Willd. showed a strong absorbance band near $450 \mathrm{~nm}$. Resonance plasmon band in the region of $400 \mathrm{~nm}$ to $500 \mathrm{~nm}$ was an indication of the presence of silver nanoparticles [22]. Optimization was carried out by doing a number of reactions by varying the amounts of salt to plant ratio (Figure 2). The best optimized $\mathrm{AgNO}_{3} /$ plant ratio selected for further studies was 10:1.

Stability check of Ag-NPs stabilized with Justicia diffusa Willd.

Stability of prepared silver nanoparticles stabilized with Justicia diffusa Willd. was checked by varying the $\mathrm{pH}$, heat and $\mathrm{NaCl}$ of the solution. Effect of $\mathrm{pH}$ on the bioinspired synthesis of silver nanoparticles by Justicia diffusa Willd. was tested over a wider $\mathrm{pH}$ range (pH1-14) as shown in the (Figure 2). Maximum absorption was observed at $\mathrm{pH}$ 13-14. Larger size nanoparticles were synthesized at low $\mathrm{pH}$ (acidic), whereas, at higher $\mathrm{pH}$, smaller sized NP synthesis was observed (Figure 2) [23]. At lower $\mathrm{pH}(\mathrm{pH} 1-4)$ large nanoparticles were synthesized, whereas at high $\mathrm{pH}$ (pH 8-14) highly dispersed and small nanoparticles were synthesized. At high pH blue shift in SPR clearly indicates the formation of small particles. At $\mathrm{pH} 2$, there was red shift due to the fact that higher positive charges at the surface of nanoparticles attracted negative charge biomass. Again blue shift was observed at high $\mathrm{pH}$ due to the presence of hydroxyl ion on the surface of nanoparticles, repulsive forces dominated in colloidal solution and thus particle aggregation is reduced. The optimum conditions were found to be $\mathrm{pH}$ (13-14).

Stability of silver nanoparticles stabilized with Justicia diffusa Willd. was checked by varying the concentration of $\mathrm{NaCl}$ solution. Different concentrations of salt were added to AgNPs and their UV-Vis spectra were obtained which that increasing concentration of salt can decrease stability of NPs. The reason for decreasing stability of nanoparticles with elevating concentration is due to halide ions. High concentration of salt resulted in aggregation by increasing the ionic strength of solutions (Figure 2). It showed that NPs are more stable in distilled water than in salt solution [24].

The effect of temperature on rate of formation of AgNPs capped with Justicia diffusa Willd. was studied. At room temperature sharp peak with narrow band is obtained. But when the NPs are subjected to a temperature of $50{ }^{\circ} \mathrm{C}$ there was increase in the SPR and also a sharp peak is obtained indicating the formation of monodisperse AgNPs [25]. Further raising the temperature broad peak with low absorption intensity is obtained indicating the formation of polydispersed nanoparticles due to denaturing of protein capping at high temperature. This brings changes in nucleation of $\mathrm{Ag}^{+}$species and growth rate (Figure 2).

SEM images show that the NPs were nearly spherical in shape (Figure 3d) which was confirmed by TEM image (Figure 3a). The major sizes of AgNPs prepared from Justicia diffusa Willd. leaves extracts were 11, 14 and $20 \mathrm{~nm}$, respectively [11]. Further AFM images showed the detailed size and morphology of AgNPs [26] (Figure 2). 

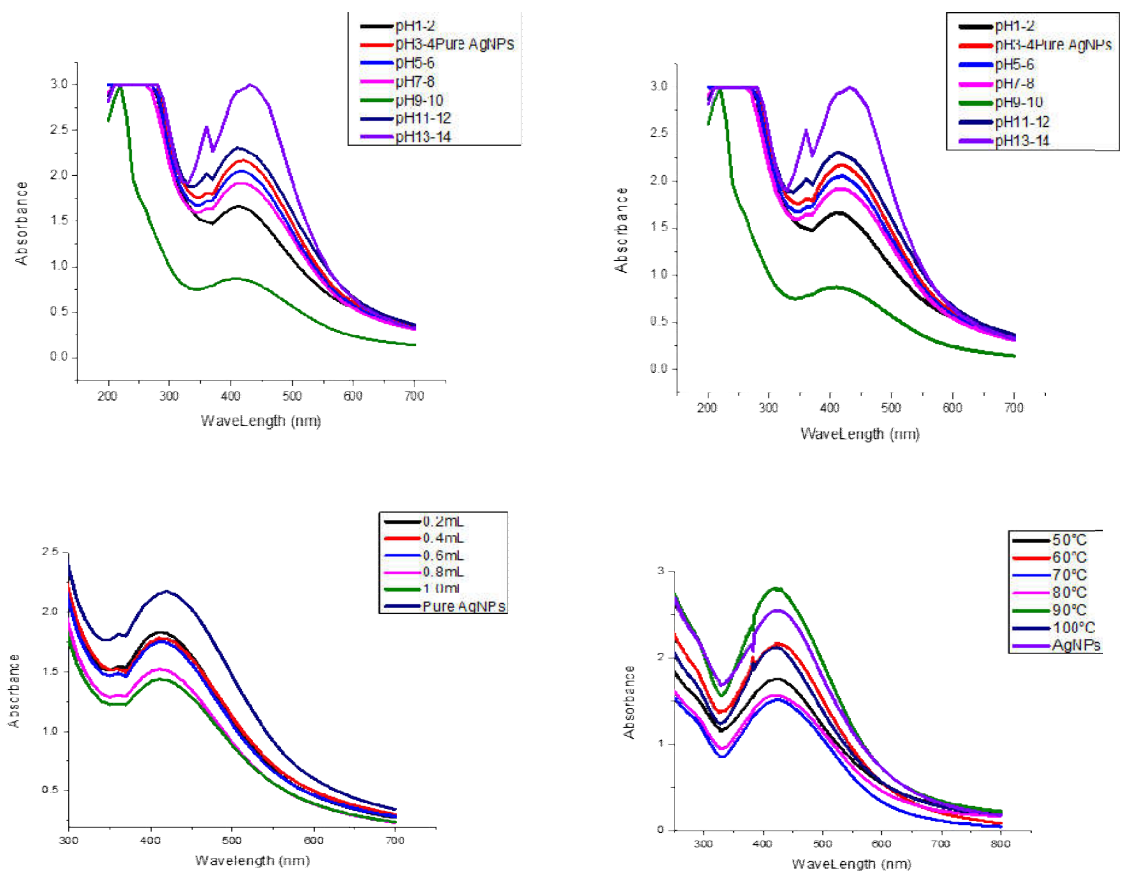

Figure 2. UV-visible spectra of Ag NPs/Justicia diffusa Willd. (a) UV-visible spectra of Ag $\mathrm{NPs} /$ Justicia diffusa Willd. having different $\mathrm{AgNo}_{3} /$ plant ratios. (b) Effect of $\mathrm{pH}$ on the stability of Ag NPs. (c) Effect of salt $(\mathrm{NaCl})$ on the stability of Ag NPs. (d) Effect of temperature on the stability of Ag NPs.

DPPH Antioxidant Assay

DPPH radical scavenging assay was investigated for the evaluation of antioxidant potential of Justicia diffusa Willd. extract and AgNPs capped with Justicia diffusa Willd. The percentage inhibition was increased in a dose dependent manner for both the plant extract and silver nanoparticles. For lowest concentration $(7.4 \mu \mathrm{g} / \mathrm{mL})$ of plant extract the percentage inhibition was 15.76 which increases to 63.33 when the concentration was increased to $200 \mu \mathrm{g} / \mathrm{mL}$. However, for AgNPs the percent inhibition values recorded were 18.90 for the concentration of $7.4 \mu \mathrm{g} / \mathrm{mL}$ and 67.70 for the concentration of $200 \mu \mathrm{g} / \mathrm{mL}$, these values specify the better antiradical potential of synthesized AgNPs than the extracts alone. $\mathrm{IC}_{50}$ value is half maximal $(50 \%)$ inhibitory concentration which is a measure of effectiveness of a substance. Percentage inhibition of plant extracts/nano-particles was calculated by formula at different concentrations i.e. $200,66.6,33.3$ and $7.4 \mu \mathrm{g} / \mathrm{mL}$ and then $\mathrm{IC}_{50}$ value (the concentration of plant extract/nanopartical at which $50 \%$ inhibition is achieved) was calculated by graphical method by using Table curve software. The synthesized AgNPs displayed better antioxidant activity in comparison to the Justicia diffusa Willd. extract (Figure 5a) [27]. 


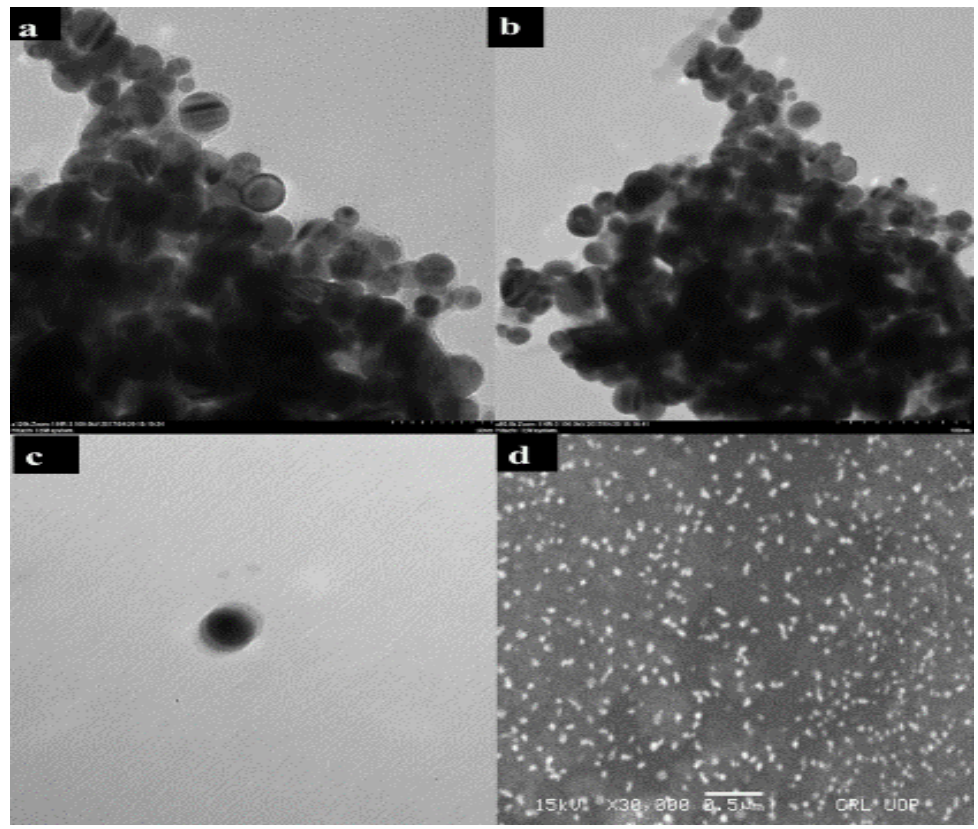

Figure 3. TEM and SEM images of Justicia diffusa Willd. extract after reaction with Ag+ ions for $72 \mathrm{~h}$ at different magnifications(A-D). The scale bars in A-C correspond to 100, 50 and $20 \mathrm{~nm}$. respectively.

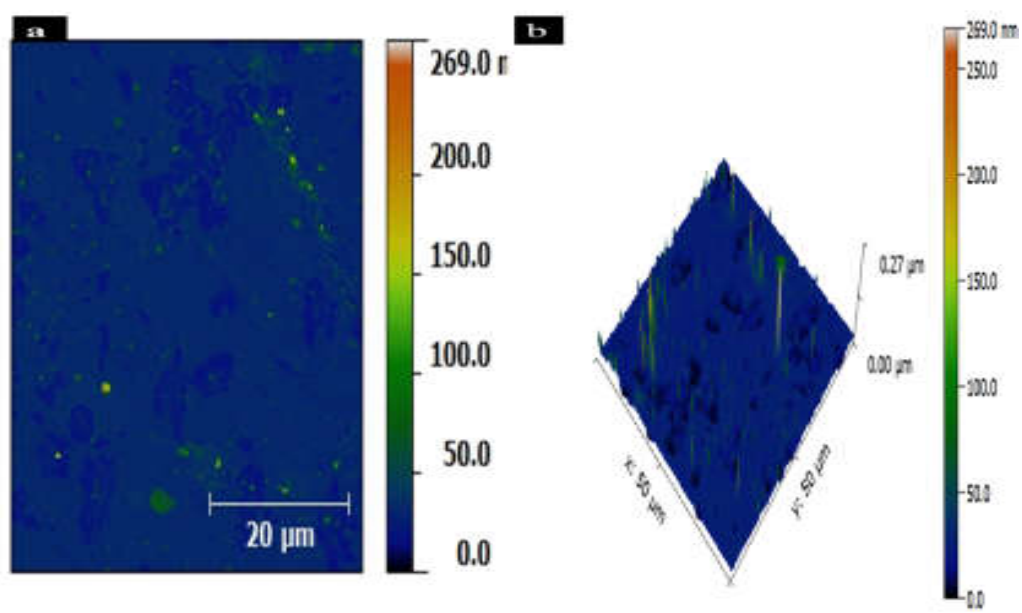

Figure 4. AFM images of Justicia diffusa Willd. extract after reaction with Ag+ ions for $72 \mathrm{~h}$. 

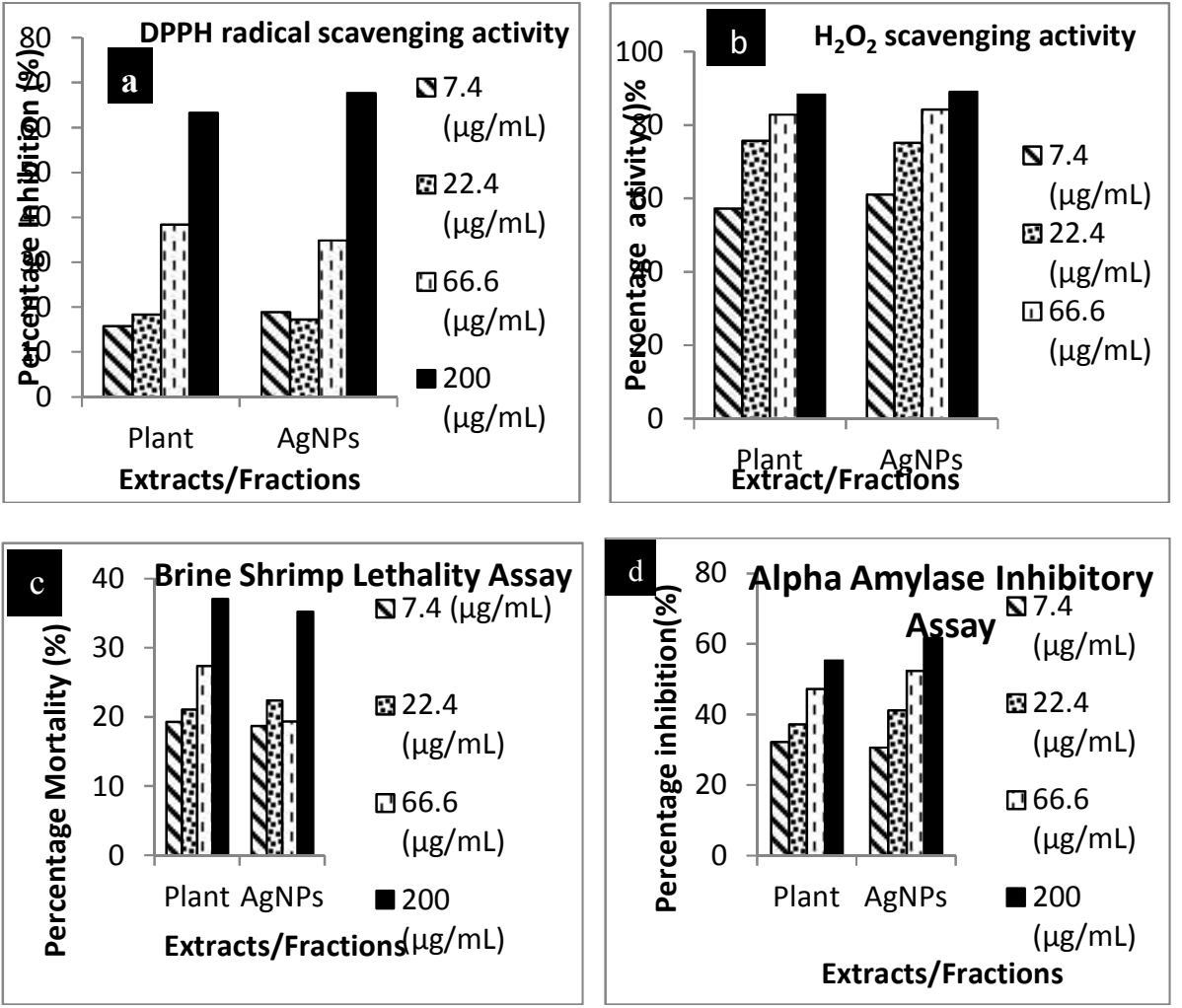

Figure 5. Antiradical, hydrogen peroxide, brine shrimp and $\alpha$-amylase assay of plant extract and synthesized Ag NPs at different concentrations.

Hydrogen peroxide scavenging activity

Plant extract and AgNPs capped with plant extract showed $\mathrm{H}_{2} \mathrm{O}_{2}$ scavenging activity by transferring electrons to $\mathrm{H}_{2} \mathrm{O}_{2}$ and neutralize it into water. $\mathrm{H}_{2} \mathrm{O}_{2}$ inhibition activity assay plays a significant role for the determination of antioxidant activity [28].

Justicia diffusa Willd. extract and AgNPs capped with Justicia diffusa Willd. showed a dose dependent response. There was consistent increase with concentration in reducing power of plant extract as well as AgNPs. Also AgNPs exhibit better $\mathrm{H}_{2} \mathrm{O}_{2}$ scavenging activity than the plant extract. The synthesized AgNPs displayed better antioxidant activity in comparison to the Justicia diffusa Willd. extract (Figure 5b). The $\mathrm{H}_{2} \mathrm{O}_{2}$ scavenging activity of plant extract will be due to phytocompounds present in the extract. On the other hand, the observed increase in $\mathrm{H}_{2} \mathrm{O}_{2}$ scavenging activity of AgNPs capped with Justicia diffusa Willd. (96\%) may be because of the plant condensed tannins present in the extract that are involved in confirmation of nanoparticles [28]. 
Brine shrimp cytotoxic assay

The cytotoxic potential of plant extract and AgNPs capped with the extract were evaluated by brine shrimp bio-assay. The $\mathrm{IC}_{50}$ values on the cytotoxicity of the synthesized colloidal AgNPs was $271 \mu \mathrm{g} \mathrm{mL}^{-1}$ (Table 1), whereas the highest mortality was observed at $200 \mu \mathrm{g} \mathrm{mL}^{-1}$ concentration. Lethality was found to be directly proportional to the concentration of AgNPs (Figure $5 \mathrm{c}$ ). The $\mathrm{IC}_{50}$ value also suggests that AgNPs have better cytotoxic potential than the plant extract alone. In accordance with the present study, Kumar et al. have reported $100 \%$ mortality of $A$. salina at $100 \mathrm{nM}$ concentration of the AgNPs synthesized by Sargassum ilicifolium. Therefore, the biosynthesized AgNPs can definitely be used as an ecofriendly antibiofilm agent against marine biofilm forming microorganisms and to prevent further succession. [29].

\section{Alpha-amylase inhibitory assay}

Studies showed that the biosynthesized AgNPs show significant $\alpha$ - amylase inhibitory activity as compared to plant extract. There was a dose-dependent increase in percentage inhibitory activity against $\alpha$-amylase enzyme. At a concentration of $7.4 \mu \mathrm{g} / \mathrm{mL}$ extract showed a percentage inhibition 32.20 and for $200 \mu \mathrm{g} / \mathrm{mL}$, it was 55.30 (Figure $5 \mathrm{~d}$ ). Also this inhibition by AgNPs (at concentration ranging from $7.4 \mu \mathrm{g} / \mathrm{ml}$ to $200 \mu \mathrm{g} / \mathrm{mL}$ ) was found to be 30.70 and 61.70. The $\mathrm{IC}_{50}$ values of both extract and synthesized AgNPs are conveyed in (Table 1). It is clear that AgNps synthesized from Justicia diffusa Willd. demonstrated high inhibitory activity against $\alpha$-amylase as compared to the plant extract [30].

\section{Reducing power}

The electron donating capacity (reducing power) of compound is associated with antioxidant activity [31]. The reducing power of silver nanoparticles increases in dose dependent manner. The obtained results show that at lower concentration silver nanoparticles shown more reducing power than that of plant extract. Reducing power is evaluated by the transformation of $\mathrm{Fe}^{3+}$ to $\mathrm{Fe}^{2+}$ in presence of compound [32]. The reducing capacity of silver nanoparticles gives an indication of its potential antioxidant activity.

\section{CONCLUSION}

We followed a simple, ecofriendly biological method for synthesis of AgNPs using Justicia diffusa. The synthesis process was quite rapid and completed outside the plant cells. The presence of AgNPs were first observed visually by color change from light green to dark brown. Further UV Vis spectroscopy was used to confirm the formation of silver nanoparticles which gives a peak at $450 \mathrm{~nm}$. The transmission electron microscopy shows that $50 \mathrm{~nm}$ size particles were prepared. These nanoparticles shows excellent antioxidant, antidiabetic and cytotoxic properties in comparison to plant extract. This shows that nanoparticles capped with Justicia diffusa exhibit better activities in comparison to plant extract. The produced silver ions were evaluated as a potential free radical scavenger when compared with the standard. The free radical causing diseases like atherosclerosis, cancer, inflammatory joint disease, asthma, diabetes, senile dementia and degenerative eye disease can be prevented with antioxidant property. Therefore, silver nanoparticles will be the best option for therapeutic or medical applications. 


\section{REFERENCES}

1. Edelstein, A.S.; Cammaratra, R. Nanomaterials: Synthesis, Properties and Applications. CRC Press: Boca Raton; 1998.

2. Bhattacharya, R.; Mukherjee, P. Biological properties of "naked" metal nanoparticles. Adv. Drug Deliv. Rev. 2008, 60, 1289-1306.

3. (a) Simkiss, K.; Wilbur, K.M. Biomineralization, Elsevier: Amsterdam; 2012; (b) Mann, S. Biomimetic Materials Chemistry. John Wiley and Sons: New York; 1995.

4. Elblbesy, M.A.-A.; Madbouly, A.K.; Hamdan, T. A.-A. Bio-synthesis of magnetite nanoparticles by bacteria. Am. J. Nano Res. Appl. 2014, 2, 98-103.

5. Ali, Z.A.; Yahya, R.; Sekaran, S.D.; Puteh, R. Green synthesis of silver nanoparticles using apple extract and its antibacterial properties. Adv. Mater. Sci. Eng. 2016, 2016, Article ID 4102196. DOI: 10.1155/2016/4102196.

6. Kim, H.K.; Choi, M.-J.; Cha, S.-H.; Koo, Y.K.; Jun, S.H.; Cho, S.; Park, Y. Earthworm extracts utilized in the green synthesis of gold nanoparticles capable of reinforcing the anticoagulant activities of heparin. Nanoscale Res. Lett. 2013, 8:542. DOI: 10.1186/1556276X-8-542.

7. Narayanan, K.B.; Sakthivel, N. Coriander leaf mediated biosynthesis of gold nanoparticles. Mater. Lett. 2008, 62, 4588-4590.

8. Shahi, S.K.; Patra, M. Microbially synthesized bioactive nanoparticles and their formulation active against human pathogenic fungi. Rev. Adv. Mater. Sci. 2003, 5, 501-509.

9. Saifuddin, N.; Wong, C.; Yasumira, A. Rapid biosynthesis of silver nanoparticles using culture supernatant of bacteria with microwave irradiation. J. Chem. 2009, 6, 61-70.

10. Christensen, L.; Vivekanandhan, S.; Misra, M.; Mohanty, A.K. Biosynthesis of silver nanoparticles using Murraya koenigii (curry leaf): An investigation on the effect of broth concentration in reduction mechanism and particle size. Adv. Mater. Lett. 2011, 2, 429-434.

11. Bhakya, S.; Muthukrishnan, S.; Sukumaran, M.; Muthukumar, M. Biogenic synthesis of silver nanoparticles and their antioxidant and antibacterial activity. Appl. Nanosci. 2016, 6, 755-766.

12. Isaac, R.; Sakthivel, G.; Murthy, C. Green synthesis of gold and silver nanoparticles using Averrhoa bilimbi fruit extract. J. Nanotechnol. 2013, 2013. Article ID 906592. DOI: $10.1155 / 2013 / 906592$.

13. Saxena, A.; Tripathi, R.; Zafar, F.; Singh, P. Green synthesis of silver nanoparticles using aqueous solution of Ficus benghalensis leaf extract and characterization of their antibacterial activity. Mater. Lett. 2012, 67, 91-94.

14. Perveen, A.; Qaiser, M. Pollen flora of Pakistan-LXVII: Acanthaceae. Pak. J. Bot. 2010, 42, 175-191.

15. Kulisic, T.; Radonic, A.; Katalinic, V.; Milos, M. Use of different methods for testing antioxidative activity of oregano essential oil. Food Chem. 2004, 85, 633-640.

16. Obied, H.K.; Allen, M.S.; Bedgood, D.R.; Prenzler, P.D.; Robards, K.; Stockmann, R. Bioactivity and analysis of biophenols recovered from olive mill waste. J. Agric. Food Chem. 2005, 53, 823-837.

17. Ruch, R.J.; Cheng, S.-j.; Klaunig, J.E. Prevention of cytotoxicity and inhibition of intercellular communication by antioxidant catechins isolated from Chinese green tea. Carcinogenesis 1989, 10, 1003-1008.

18. Oyaizu, M. Studies on products of browning reaction: Antioxidative activities of products of browning reaction prepared from glucosamine. Jpn. J. Nutr. Diet 1986, 44, 307-315.

19. Meyer, B.N.; Ferrigni, N.R.; Putnam, J.E.; Jacobsen, L.B.; Nichols, D.E.; McLaughlin, J.L. Brine shrimp: A convenient general bioassay for active plant constituents. Planta Med. 1982, 45, 31-34. 
20. Gadir, S. Assessment of bioactivity of some Sudanese medicinal plants using brine shrimp (Artemia salina) lethality assay. J Chem Pharm Res 2012, 4 (12), 5145-4148.

21. Sudha, P.; Zinjarde, S.S.; Bhargava, S.Y.; Kumar, A.R. Potent $\alpha$-amylase inhibitory activity of Indian Ayurvedic medicinal plants. BMC Complement. Altern. Med. 2011, 11:5. DOI: 10.1186/1472-6882-11-5.

22. Ahmad, N.; Sharma, S.; Singh, V.; Shamsi, S.; Fatma, A.; Mehta, B. Biosynthesis of silver nanoparticles from Desmodium triflorum: a novel approach towards weed utilization. Biotechnol. Res. Int. 2011, 2011, Article ID 454090. DOI: 10.4061/2011/454090.

23. Iravani, S.; Zolfaghari, B. Green synthesis of silver nanoparticles using Pinus eldarica bark extract. BioMed Res. Int. 2013, 2013, Article ID 639725. DOI: 10.1155/2013/639725.

24. Naz, S.S.; Islam, N.U.; Shah, M.R.; Alam, S.S.; Iqbal, Z.; Bertino, M.; Franzel, L.; Ahmed, A. Enhanced biocidal activity of $\mathrm{Au}$ nanoparticles synthesized in one pot using 2,4dihydroxybenzene carbodithioic acid as a reducing and stabilizing agent. J. Nanobiotechnol. 2013, 11:13. DOI: 10.1186/1477-3155-11-13.

25. Amin, M.; Anwar, F.; Janjua, M.R.S.A.; Iqbal, M.A.; Rashid, U. Green synthesis of silver nanoparticles through reduction with Solanum xanthocarpum L. berry extract: Characterization, antimicrobial and urease inhibitory activities against Helicobacter pylori. Int. J. Mol. Sci. 2012, 13, 9923-9941.

26. Logeswari, P.; Silambarasan, S.; Abraham, J. Synthesis of silver nanoparticles using plants extract and analysis of their antimicrobial property. J. Saudi Chem. Soc. 2015, 19, 311-317.

27. (a) Parveen, M.; Ahmad, F.; Malla, A.M.; Azaz, S. Microwave-assisted green synthesis of silver nanoparticles from Fraxinus excelsior leaf extract and its antioxidant assay. Appl. Nanosci. 2016, 6, 267-276; (b) Dipankar, C.; Murugan, S. The green synthesis, characterization and evaluation of the biological activities of silver nanoparticles synthesized from Iresine herbstii leaf aqueous extracts. Colloids Surf B: Biointerf. 2012, 98, 112-119.

28. Subramanian, R.; Subbramaniyan, P.; Raj, V. Antioxidant activity of the stem bark of Shorea roxburghii and its silver reducing power. SpringerPlus 2013, 2:28. DOI: 10.1186/2193-1801-2-28.

29. Kumar, P.; Selvi, S.S.; Praba, A.L.; Selvaraj, M.; Rani, L.M.; Suganthi, P.; Devi, B.S.; Govindaraju, M. Antibacterial activity and in-vitro cytotoxicity assay against brine shrimp using silver nanoparticles synthesized from Sargassum ilicifolium. Digest J. Nanomater. Biostruct. 2012, 7, 1447-1455.

30. Das, M.P.; Devi, P.V.; Yasmine, Y. Assessment of in vitro anti-diabetic activity of Ficus glomerata. Der Pharma. Lett. 2016, 8, 267-272.

31. Yen, G.C.; Duh, P.D.; Tsai, C.L. Relationship between antioxidant activity and maturity of peanut hulls. J. Agric. Food Chem. 1993, 41, 67-70.

32. Gülçın, İ.; Oktay, M.; Kıreçc1, E.; Küfrevığlu, Ö.İ. Screening of antioxidant and antimicrobial activities of anise (Pimpinella anisum L.) seed extracts. Food Chem. 2003, 83, 371-382. 